\title{
TEXTURE AND COERCIVE FORCE OF THE METAL OF FURNACE TUBE COILS
}

\author{
N. M. Shkatulyak ${ }^{1}$, E. A. Dragomeretskaya ${ }^{1}$, V. V. Usov ${ }^{1}$, M. D. Rabkina ${ }^{2}$, A. L.Palienko ${ }^{2}$ \\ ${ }^{1}$ South Ukrainian National Pedagogical University named after K.D. Ushinsky \\ 26 Staroportofrankovskaya Str., 65020, Odessa, Ukraine \\ ${ }^{2}$ E.O. Paton Electric Welding Institute of the National Academy of Sciences of Ukraine \\ 11 Bozhenko Str. 03150, Kiev, Ukraine
}

\begin{abstract}
*Corresponding author. E-mail: valentin usov50@,mail.ru; address for correspondence: 59 Kolontaevskaya Str., Apt. 8, 65091, Odessa, Ukraine. Tel. +(38) 0663529092
\end{abstract}

The crystallographic texture of the metal of tubular samples carved from furnace coils, involved in the processing of oil after various periods of operation, was studied by X-ray diffraction by means of constructing inverse pole figures. The texture of the $15 \mathrm{Kh} 5 \mathrm{M}$ ferritic chromiummolybdenum steel and the $08 \mathrm{Kh} 18 \mathrm{~N} 10 \mathrm{~T}$ austenitic chromium-nickel steel was studied in the normal direction (ND) to the surface of the tubes, in the rolling direction (RD) coinciding with the tube axis and in the transverse direction (TD) coinciding with the tangential (circumferential) direction of the tubes. The coercive force was measured in the axial and circumferential directions. The coercive force in RD exceeds its value in TD. This difference is due to crystal magnetic anisotropy caused by the crystallographic texture. Although the X-ray phase analysis of the tubular samples of the furnace coils made of the $08 \mathrm{Kh} 18 \mathrm{~N} 10 \mathrm{~T}$ stainless steel has not revealed the presence of the ferromagnetic phase, there is anisotropy of the coercive force. Possible reasons for the phenomenon are discussed. anisotropy.

Keywords: furnace coil, crystallographic texture, coercive force, crystal magnetic

DOI: $10.17804 / 2410-9908.2016 .1 .029-037$

\section{References}

1. Kurc-Lisiecka A., Ozgowicz W., Ratuszek W., Chruściel K. Texture and structure evolution during cold rolling of austenitic stainless steel. Journal of Achievements in Materials and Manufacturing Engineering, 2012, vol. 52, iss. 1, pp. 22-30.

2. Usov V.V., Shkatulyak N.M., Girenko V.S., Rabkina M.D., Bernatsky A.V., Musienko A.P., Shcherbakov O.N. Effect of crystallographic texture on the tendency to brittle fracture of layered low-alloy low-pearlitic steels. Izv. Acad. Nauk SSSR. Metally, 1990, no. 1, pp. 120-125. (In Russian).

3. Lyakishev N.P., Shamrai V.F., Egiz I.V., Efron L.I., Izotov V.I., Matrosov Yu.I. Crystallographic texture and mechanical properties of the steel sheet. Metally, 2003, iss. 4, pp. 93-100. (In Russian).

4. Gorkunov E.S., Savrai R.A., Makarov A.V, Zadvorkin S.M. Magnetic techniques for estimating elastic and plastic strains in steels under cyclic loading. Diagnostics, Resource and Mechanics of materials and structures, 2015, iss. 2, pp. 6-15. DOI: 10.17804/2410-9908.2015.2.006-015. Available at: http://dream-journal.org.

5. Lobanov L.M., Nekhotyashchy V.A., Rabkina M.D., Usov V.V., Shkatulyak N.M., Tkachuk E.N. Anisotropy of the coercive force and texture of deformed steel. Deformatsiya $i$ razrushenie materialov, 2010, no. 10, pp. 19-24. (In Russian).

6. Kuzeev I.R., Tukaeva R.B., Bayazitov M.I., Abyzgildina S.S. Osnovnoye oborudovaniye tekhnologicheskikh ustanovok NPZ [The Main Equipment of the Refinery Process Units]. Ufa, UGNTU Publ., 2013, 129 p. (In Russian). 
7. Vishnyakov Ya.D., Babareko A.A., Vladimirov S.A., Egiz I.V. Teoriya obrazovaniya tekstur $v$ metallakh $i$ splavakh [The Theory of the Formation of Textures in Metals and Alloys]. M., Nauka Publ., 1979, 343 p. (In Russian).

8. Danilov S.V., Kalinin A.A. [The texture of hot-rolled anisotropic electrical steel]. XV Mezhdunarodnaya nauchno-tekhnicheskaya uralskaya shkola-seminar metallovedov molodykh uchenykh. Ekaterinburg, URFU Publ., 2014, pp. 293-295. (In Russian). Available at: http://hdl.handle.net/10995/29761.

9. Canova G.R., Kockss U.F., Jonas J.J. Theory of torsion texture development. Acta Metallurgica, 1984, vol. 32, iss. 2, pp. 211-226. DOI: 10.1016/0001-6160(84)90050-6.

10. [Manufacturing technology of seamless pipes]. Svarka metalla. (In Russian). Available at: http://www.tehnoarticles.ru/svarkametalla/14.html.

11. Preobrazhensky A.A., Bishard E.G. Magnitnye materialy i elementy [Magnetic Materials and Elements]. M., Vysshaya Shkola Publ., 1986, 352 p. (In Russian).

12. Cayron C. One-step model of the face-centred-cubic to bodycentred-cubic martensitic transformation. Acta Crystallographica Section A: Foundations of Crystallography, 2013, vol. 69, iss. 5, pp. 498-509. DOI: 10.1107/S0108767313019016. 
Подана в журнал: 24.12 .2015

УДК 669-176:548.4

DOI: $10.17804 / 2410-9908.2016 .1 .029-037$

\title{
ТЕКСТУРА И КОЭРЦИТИВНАЯ СИЛА ТРУБЧАТЫХ ПЕЧНЫХ ЗМЕЕВИКОВ
}

\author{
Н. М. Шкатуляк ${ }^{1}$, Е. А. Драгомерецкая ${ }^{1}$, В. В. Усов ${ }^{1 *}$, М. Д. Рабкина ${ }^{2}$, А. Л.Палиенко ${ }^{2}$ \\ ${ }^{1}$ Южно-украинский национальный педагогический университет им. К.Д. Уиинского, \\ ул. Старопортофранковская, 26, 65020, г. Одесса, Украина \\ ${ }^{2}$ Институт электросварки им. Е.О. Патона НАНУ, ул. Боженко, 11, 03150, г. Киев, Украина \\ * Ответственный автор. Электронная почта: valentin_usov50@mail.ru; адрес для переписки: \\ ул. Колонтаевская, 59, кв. 8, 65091, г. Одесса, Украина. Телефон: +(38) 0663529092.
}

Рентгеновским методом с помощью построения обратных полюсных фигур исследована кристаллографическая текстура металла трубчатых образцов, вырезанных из змеевиков печей, участвующих в процессе переработки нефти после различных сроков их эксплуатации. Текстуру хромомолибденовой ферритной стали $15 \mathrm{X} 5 \mathrm{M}$ и хромоникелевой аустенитной стали 08X18Н10Т изучали в направлении нормали (НH) к поверхности труб, направлении прокатки (НП), совпадающем с осью труб, и поперечном направлении (ПН), совпадающем с тангенциальным (кольцевым) направлением труб. Коэрцитивную силу измеряли в осевом и кольцевом направлениях. Коэрцитивная сила в НП превышает ее значение в ПН. Это различие объясняется кристаллической магнитной анизотропией, обусловленной кристаллографической текстурой. Хотя рентгенографический фазовый анализ трубчатых образцов печных змеевиков из нержавеющей стали 08X18Н10Т не выявил наличия ферромагнитной фазы, имеет место анизотропия коэрцитивной силы. Обсуждаются возможные причины явления.

Ключевые слова: печной змеевик, кристаллографическая текстура, коэриитивная сила, кристаллическая магнитная анизотропия.

\section{1. Введение}

Материалом для змеевиков трубчатых печей в нефтеперерабатывающих комплексах (НПК) служат преимущественно теплостойкие стали типа $15 \mathrm{X} 5 \mathrm{M}$ и жаростойкие стали типа 08X18Н10Т (НПК). Данные стали регламентируются ГОСТами, в частности по химсоставу и механическим свойствам, однако характеристики структуры, имеющие при этом определяющее значение, в частности кристаллографическая текстура, не находят отражение в нормативных документах. Ранее проводились исследования формирования текстуры в листовых полуфабрикатах вышеназванных сталей при горячей и холодной прокатке [1]. Однако текстура труб из вышеупомянутых сталей практически не исследована. В то же время неблагоприятная кристаллографическая текстура облегчает распространение хрупких слоистых трещин [2, 3], что может привести к выходу из строя оборудования. Поэтому мониторинг структурного состояния элементов конструкций и систем оборудования НПК - актуальная задача физики прочности и пластичности. Перспективными являются неразрушающие методы магнитного контроля структурных изменений и деградации ферромагнитных материалов, развиваемые, например, в [4]. Одним из перспективных методов неразрушающего контроля структурного состояния сталей мог бы стать метод измерения коэрцитивной силы в элементах оборудования, работающих в экстремальных условиях. Однако для внедрения этого метода в практику контроля необходимо исследовать корреляцию коэрцитивной силы с характеристиками структуры, в частности кристаллографической текстуры. Ранее были найдены значимые корреляционные связи и получены соответствующие линейные уравнения регрессии с высокими значениями коэффициента надежности аппроксимации между значениями полюсной плотности на обратных полюсных фигурах (ОПФ) направления прокатки (НП) 
$P_{h k l} I I I \quad$ и поперечного направления (ПН) $P_{h k l} \dddot{I I} \quad$ и значениями коэрцитивной силы $H_{c} I \ddot{I}$ и $H_{c} \ddot{I I} \quad$ листов и цилиндрических оболочек из стали 08кп [5].

Цель данной работы - исследование кристаллографической текстуры и коэрцитивной силы трубчатых элементов из хромомолибденовой стали $15 \mathrm{X} 5 \mathrm{M}$ и нержавеющей аустенитной стали 08X18Н10T.

\section{2. Материал и методика исследований}

Материалами для исследований послужили образцы стали $15 \mathrm{X} 5 \mathrm{M}$ из змеевика диаметром 219 мм с толщиной стенки 9 мм, отработавшего порядка 270000 часов, а также - стали 08Х18Н10Т из змеевика диаметром 152 мм с толщиной стенки 8 мм после 140000 ч эксплуатации. Длина исследуемых трубчатых образцов была 1000 мм. Известно, что для изготовления печей НПК используют бесшовные цельнотянутые трубы [6]. Коэрцитивную силу измеряли с помощью стандартного коэрцитиметра КРМ-Ц-К2М в тангенциальном (кольцевом) направлении $\left(H_{c} \perp\right)$ и вдоль оси труб $\left(H_{c} \|\right)$ не менее 5 раз в различных участках труб. В качестве величины коэрцитивной силы в соответствующем направлении трубы принимали среднее арифметическое значение. Для обеспечения более точных и стабильных значений коэрцитивной силы вдоль оси трубчатого образца применяли специальное приспособление, с помощью которого полюсные наконечники датчика коэрцитиметра располагались строго в осевом направлении. Для измерений коэрцитивной силы в кольцевом направлении для труб диаметром более 40 мм приспособления не требуется, так как датчик занимает устойчивое положение. Квадратные полюсные наконечники датчика имели размеры $33 \times 33$ мм, расстояние между внутренними сторонами которых составило 32,4 мм.

Для исследования текстуры вырезали прямоугольные образцы с длиной диагонали 24 мм для установки в кювету штатной текстурной приставки гониометра ДРОН-3м. Текстуру исследовали рентгеновским методом с построением обратных полюсных фигур направления нормали (НН) к поверхности трубы, направления прокатки (НП), совпадающего с осевым направлением трубы, и поперечного (тангенциального) направления (ПН), перпендикулярного к стенке трубы, - соответственно ОПФ НН, ОПФ НП и ОПФ ПН. Перед рентгеновскими исследованиями текстуры в НН цилиндрические поверхности труб шлифовали для получения плоской поверхности. Для исследования текстуры при отражении от плоскостей образцов перпендикулярных НП и ПН с целью увеличения облучаемой поверхности изготавливали наборные образцы, состоящие из наклеенных друг на друга кусочков, ориентированных соответствующими плоскостями перпендикулярно НП и ПН соответственно. Перед исследованием текстуры соответствующие исследуемые поверхности химически полировали на глубину 0,1 мм для удаления искаженного механической обработкой слоя.

На дифрактометре ДРОН-3м проводили сканирование по углам $\theta-2 \theta$ в фильтрованном излучении $K_{\alpha}$ - молибдена. Записывали дифрактограммы линий (110), (200), (211), (220), (310), (222), (321), (400) для образцов из стали 15Х5М и образца без текстуры. Для текстурованных образцов из стали 08X18Н10Т и соответствующего образца без текстуры фиксировали дифракционные отражения от кристаллографических плоскостей (111), (200), (220), (311), (222), (331), (420), (422), (531), (620), (533), (640), (642), (733), (664), (931). Бестекстурные образцы изготовили из мелких рекристаллизованных опилок соответствующих сталей. В качестве полюсной плотности использовали отношения интегральных интенсивностей линий дифракции исследуемых образцов и эталона с нормировкой, по Моррису [7]. Приведенная полюсная плотность $P_{h k l}$ пропорциональна отношению интенсивности линии $(h k l)$ в текстурованном образце и образце без текстуры: 


$$
P_{h k l}=\frac{I_{h k l}^{T}}{I_{h k l}^{0}} K,
$$

где нормирующий множитель $K$ :

$$
K=\frac{1}{\sum_{\Delta} A_{h k l} I_{h k l}^{T} / I_{h k l}^{0}},
$$

где $\sum_{\Delta} A_{h k l}=1$. Значение коэффициентов $A_{h k l}$ приведены в [7]. Таким образом,

$$
P_{h k l}=\frac{I_{h k l}^{T} / I_{h k l}^{0}}{\sum_{\Delta} A_{h k l} I_{h k l}^{T} / I_{h k l}^{0}},
$$

где $I_{h k l}^{T}$ - интегральная интенсивность линии $\{h k l\}$ в текстурованном образце; $I_{h k l}^{0}$ - то же для образца без текстуры.

\section{3. Результаты и обсуждение}

Обратные полюсные фигуры трубчатых образцов из стали 15Х5М представлены на рис. 1.
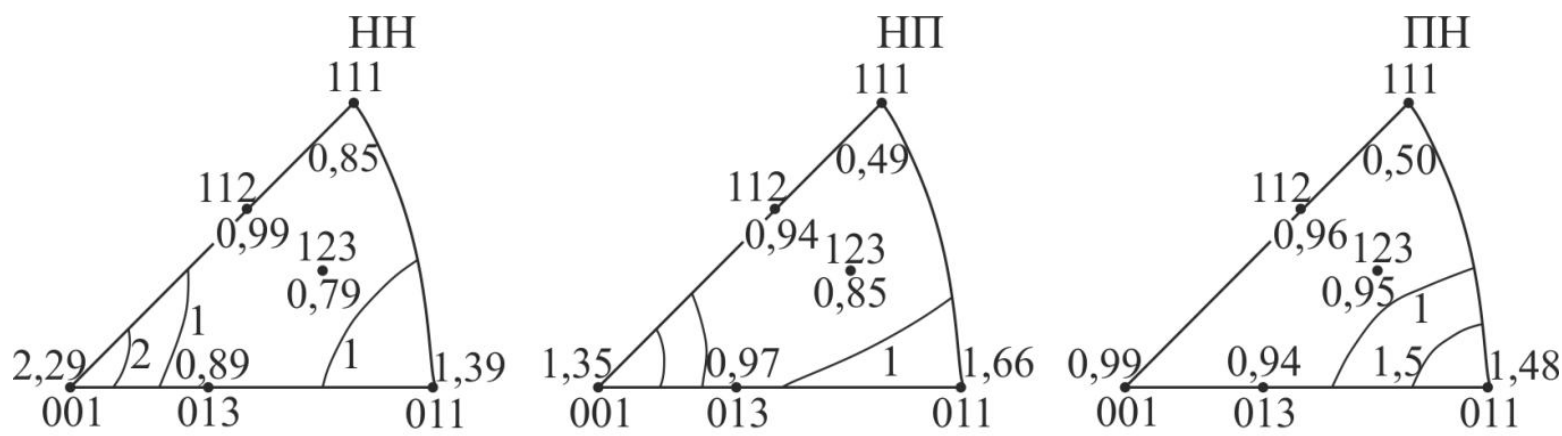

Рис. 1. Текстура трубчатых образцов из стали 15Х5М

На рис. 2 представлены ОПФ трубчатых образцов из стали 08X1810Т.
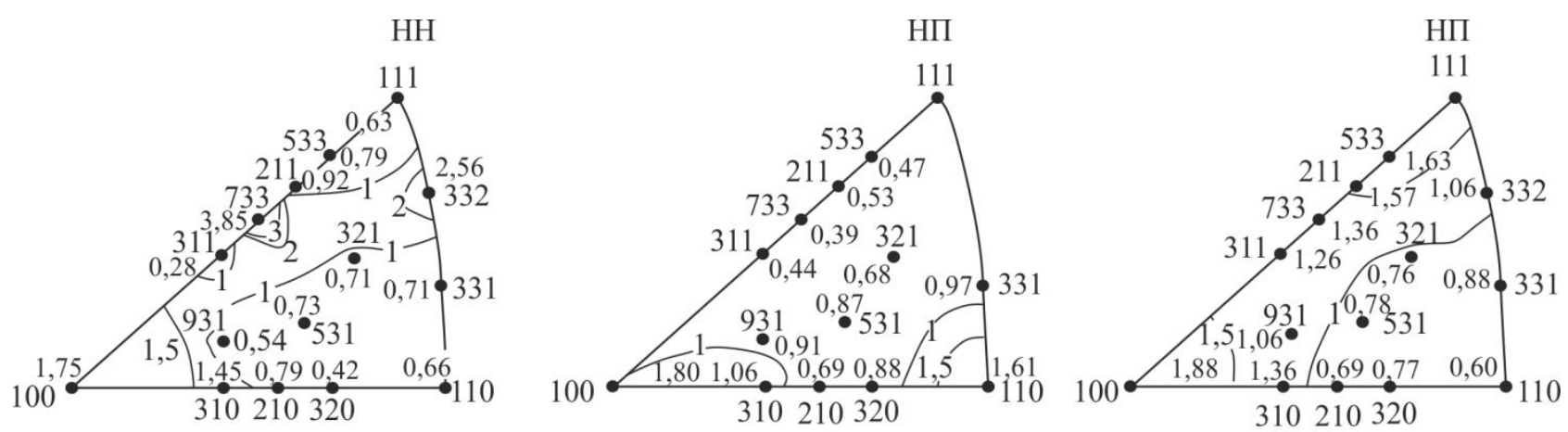

Рис. 2. Текстура трубчатых образцов из стали 08X1810Т 
Результаты измерения коэрцитивной силы приведены в таблице.

Коэрцитивная сила в трубчатых образцах печных змеевиков

\begin{tabular}{|c|c|c|}
\hline \multirow{2}{*}{ Сталь } & \multicolumn{2}{|c|}{ Коэрцитивная сила $H_{c}, \mathrm{~A} /$ см } \\
\cline { 2 - 3 } & Вдоль оси трубы & В кольцевом направлении \\
\hline 15Х5М & 6,84 & 6,14 \\
\hline $08 X 18 \mathrm{H} 10 \mathrm{~T}$ & 1,15 & 0,94 \\
\hline
\end{tabular}

На рис. 1 видно, что на ОПФ НН трубчатого образца печного змеевика из стали 15Х5М наблюдается два максимума полюсной плотности. Один величиной 2,29 - в полюсе $<001>$ и 1,39 - в полюсе $<110>$. Аналогичное распределение полюсной плотности на ОПФ НП, но с другими значениями максимумов. На ОПФ ПН при этом имеет место один максимум полюсной плотности 1,48 в полюсе $<110>$. Анализ показал, что текстура может быть описана комбинацией идеальных ориентировок $\{001\}<110>+\{110\}<100>$. Здесь и далее цифры в фигурных скобках означают индексы Миллера семейства кристаллографических плоскостей, параллельных поверхности трубы. Цифры в угловых скобках означают индексы Миллера семейства кристаллографических направлений, принадлежащих вышеуказанным кристаллографическим плоскостям и совпадающих с направлением оси трубы. Первая из ориентировок является типичной для текстуры прокатки ферритной стали. Вторая представляет собой ориентировку так называемой текстуры Госса [8]. Эта текстура является желательной в трансформаторной стали [8]. Формирование текстуры Госса в трансформаторной стали связано с протеканием вторичной рекристаллизации. В то же время текстура типа $\{110\}<100>$ является текстурой сдвига в ОЦК-металлах и сплавах [9]. Так как при изготовлении бесшовных труб применяется прокатка со скошенными валками [10], то вероятной причиной формирования текстуры $\{110\}<100>$ в трубчатом образце стали 015 Х5М является наличие сдвиговой деформации при прокатке.

Из данных таблицы видно, что наблюдается анизотропия коэрцитивной силы. Коэрцитивная сила в осевом направлении превышает ее значение в кольцевом направлении примерно в 1,12 раза.

В общем случае коэрцитивную силу можно представить как сумму составляющих, обусловленных кристаллографической магнитной анизотропией $H_{c}^{K}$, возникающими при наличии дефектов кристаллической решетки внутренними упругими напряжениями $H_{c}^{\sigma}$, и измельчением кристаллов и их вытянутостью $H_{c}^{N}[11]$ :

$$
H_{c}=H_{c}^{K}+H_{c}^{\sigma}+H_{c}^{N}=a \frac{K_{1}}{\mu_{0} I_{S}}+b \frac{\lambda_{S} \sigma}{\mu_{0} I_{S}}+c\left|N_{b}-N_{a}\right| I_{S},
$$

где $a, b, c$ - числовые коэффициенты; $K_{1}$ - константа магнитной анизотропии; $\mu_{0}$ - магнитная постоянная; $I_{S}$ - намагниченность насыщения; $\lambda_{S}$ - магнитострикция насыщения; $\sigma$ внутренние упругие напряжения; $N_{a}$ - коэффициент размагничивания в направлении главной оси частицы в форме эллипсоида; $N_{b}$ - коэффициент размагничивания в любом перпендикулярном главной оси направлении.

Максимально возможное для данного вещества значение $H_{c}^{N}$ соответствует сильно вытянутой частице, для которой [11] $H_{c}^{N}=I_{S} / 2$.

Из работы [5] следует, что между полюсной плотностью $P_{110}$ и величиной коэрцитивной силы имеет место линейная корреляция с коэффициентом надежности аппроксимации более 0,8 . Аналогичная связь прослеживается и в нашем исследовании. Можно предпо- 
ложить, что анизотропия коэрцитивной силы в трубчатых образцах стали $15 X 5 \mathrm{M}$ обусловлена, в основном, магнитной кристаллографической анизотропией вследствие кристаллографической текстуры. Повышение коэрцитивной силы в НП по сравнению с ПН может быть объяснено следующим образом. Известно, что в $\alpha$-железе и сплавах на его основе кристаллографическое направление $<100>$ является осью легкого намагничивания. Это означает, что работа намагничивания, необходимая для насыщения в направлении $<100>$, минимальна [11]. До наложения магнитного поля вектор намагниченности кристаллов был ориентирован в направлении легкого намагничивания $<100>$ [11]. При включении внешнего магнитного поля вдоль оси трубы совершаемая работа по переориентации вектора намагниченности кристаллов к направлению трудного намагничивания $<110>$ возрастает. Аналогичные процессы происходят и при наложении магнитного поля в кольцевом направлении. Но как видно из рис. 1, полюсная плотность $<110>$ вдоль оси трубы составила 1,66, а в кольцевом направлении (ПН) - 1,48, т. е. меньше в 1,12 раза, как и отношение соответствующих значений коэрцитивной силы. Таким образом, при оценке структурного состояния сталей необходимо принимать во внимание влияние кристаллографической текстуры.

Текстура трубчатых образцов печных змеевиков из стали 08X18Н9Т отличается от обычной текстуры прокатки аустенитных сталей (рис. 2). Видно, что ОПФ НН характеризуется широкой полосой повышенной полюсной плотности. Эта полоса начинается в полюсе $<001>$ и простирается до полюса $<332>$. В сочетании с ОПФ НП, где имеет место максимум в полюсе $<110>$, такое распределение ориентаций характерно для текстуры кручения типа $\{\mathrm{hkl}\}<110>$ [9], что, вероятно, обусловлено условиями прокатки бесшовных труб. При обычной текстуре прокатки листов максимум располагается в полюсе $<112>$ [1]. Второй по величине максимум полюсной плотности на ОПФ НН в полюсе $<332>$. Образование этого максимума связано с двойникованием [7]. Наличие двойников подтверждается на наших снимках микроструктуры (рис. 3). Кроме того, наблюдается также максимум 1,75 в полюсе <001>.

На ОПФ НП два максимума полюсной плотности. Один величиной 1,80 наблюдается в полюсе $<100>$, а второй - в полюсе $<110>(1,61)$.

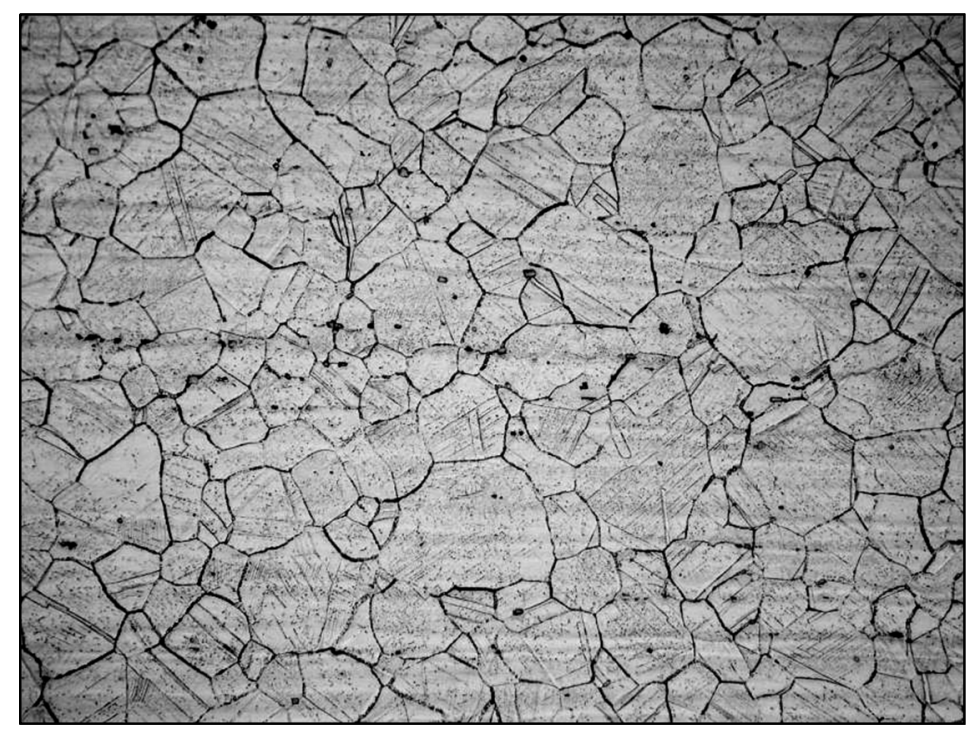

Рис. 3. Микроструктура трубчатого образца из стали 08X18Н10T.

Снято на микроскопе «Неофот $-32 »$. Увеличение $\times 200$

На ОПФ ПН видно наличие двух максимумов полюсной плотности в полюсе $<100>$ $(1,88)$ и в полюсе $<111>(1,79)$.

Анализ показал, что в текстуре присутствует кубический компонент текстуры $\{001\}<100>$, который, вероятно, связан с динамической рекристаллизацией в процессе получения труб. Имеет место также компонент текстуры сдвига $\{\mathrm{hkl}\}<110>$. Формирование ком- 
понента $\{332\}<113>$, может быть, связано со скольжением по плоскостям, параллельным границам двойников, которое ведет к анормальному вращению двойниковой матрицы вышеуказанной ориентации $\{332\}<113>[5]$.

Как видно из таблицы, в трубчатых образцах печного змеевика из нержавеющей стали 08Х19Н10Т, который эксплуатировался при температурах до $400{ }^{\circ} \mathrm{C}$, коэрцитивная сила вдоль оси трубы и в кольцевом направлении составили 1,15 и 0,94 A/см соответственно, т. е. имеет место анизотропия коэрцитивной силы, несмотря на то, что аустенит стали неферромагнитен. Однако проведенный рентгеноструктурный анализ не выявил наличия мартенситной фазы, как например, в [1]. Это может быть обусловлено тем, что кристаллы мартенсита слишком малы. Таким образом, метод измерения коэрцитивной силы обладает большей структурной чувствительностью по сравнению с рентгенофазовым анализом.

В данной работе мы не обладаем данными коэрцитивной силы и текстуры труб змеевиков до начала эксплуатации. То, что трубчатые образцы печных змеевиков из стали 08Х19Н10Т обладают магнитными свойствами, свидетельствует о том, что в процессе эксплуатации или изготовления могло произойти мартенситное превращение. Исходя из экспериментальной текстуры трубчатых образцов из стали 08X19Н10Т можно предположить, что вероятными ориентационными превращениями могли быть превращения Питча типа $\{001\}_{\gamma}\left\|\{110\}_{\alpha},\langle 110\rangle_{\gamma}\right\|\langle 111\rangle_{\alpha}$ [12]. В этом случае с осевым направлением трубы (НП) будет совпадать направление $\langle 111\rangle_{\alpha}$ наиболее трудного намагничивания, а с тангенциальным (кольцевым) направлением - $\langle 112\rangle_{\alpha}$.

При наложении внешнего магнитного поля вдоль оси трубы работа по переориентации вектора намагниченности кристаллов мартенсита, ориентированных ранее в направлении легкого намагничивания, будет больше в НП, чем при наложении магнитного поля в ПН.

\section{4. Заключение}

Текстура трубчатого образца печного змеевика из стали $15 \mathrm{X}$ М может быть описана комбинацией ориентировки типичной текстуры прокатки стали $\{001\}<110>$ и компоненты текстуры сдвига $\{110\}<100>$.

В трубчатых образцах печного змеевика из стали 15Х5М имеет место анизотропия коэрцитивной силы: ее величина в осевом и кольцевом направлении трубы составила 6,84 и $6,14 \mathrm{~A} / \mathrm{cm}$ соответственно. Анизотропия коэрцитивной силы в трубчатых образцах стали $15 X 5 \mathrm{M}$ обусловлена, в основном, магнитной кристаллографической анизотропией, связанной с увеличением работы по переориентации вектора намагниченности от направления легкого намагничивания $<100>$ до наложения поля к направлению трудного намагничивания $<110>$ при наложении магнитного поля.

Текстура трубчатых образцов печных змеевиков из стали 08X18Н9Т отличается от обычной текстуры прокатки аустенитных сталей наличием текстуры сдвига $\{\mathrm{hkl}\}<110>$ и двойниковых ориентировок $\{332\}<113>$. Проведенный рентгеновский фазовый анализ не зафиксировал наличия мартенситной фазы. При этом коэрцитивная сила имеет значение 1,15 и $0,94 \mathrm{~A} /$ см в осевом и кольцевом направлении соответственно, что свидетельствует о том, что коэрцитивная сила больше реагирует на структурные изменения по сравнению с рентгеновским фазовым анализом.

\section{Литература}

1. Texture and structure evolution during cold rolling of austenitic stainless steel / A. Kurc-Lisiecka, W. Ozgowicz, W. Ratuszek, K. Chruściel // Journal of Achievements in Materials and Manufacturing Engineering. - 2012. - Vol. 52, iss.1. - P. 22-30. 
2. Влияние кристаллографической текстуры на склонность к слоисто-хрупкому разрушению низколегированных малоперлитных сталей / В. В. Усов, Н. М. Шкатуляк, В. С. Гиренко, М. Д. Рабкина, А. В. Бернацкий, А. П. Мусиенко, О. Н. Щербаков // Изв. АН СССР. Металлы. - 1990. - № 1. - С. 120-125.

3. Кристаллографическая текстура и механические свойства листов стали / Н. П. Лякишев, В. Ф Шамрай, И. В. Эгиз, Л. И. Эфрон, В. И. Изотов, Ю. И. Матросов // Металлы. - 2003. - № 4. - С. 93-100.

4. Magnetic techniques for estimating elastic and plastic strains in steels under cyclic loading / E. S. Gorkunov, R. A. Savrai, A. V. Makarov, S. M. Zadvorkin // Diagnostics, Resource and Mechanics of materials and structures. - 2015. - Iss. 2. - P. 6-15. - DOI: 10.17804/2410-9908.2015.2.006015. - URL: http://dream-journal.org/DREAM_Issue_2_2015_Gorkunov_E.S._et_al._6_15.pdf.

5. Анизотропия коэрцитивной силы и текстура деформируемой стали / Л. М. Лобанов, В. А. Нехотящий, М. Д. Рабкина, В. В. Усов, Н. М. Шкатуляк, Е. Н. Ткачук // Деформация и разрушение материалов. - 2010. - № 10. - С. 19-24.

6. Основное оборудование технологических установок НПЗ / И. Р. Кузеев, Р. Б. Тукаева, М. И. Баязитов, С. Ш. Абызгильдина. - Уфа : Изд-во УГНТУ, 2013. - 129 с.

7. Теория образования текстур в металлах и сплавах / Я. Д. Вишняков, А. А. Бабарэко, С. А. Владимиров, И. В. Эгиз. - М. : Наука, 1979. - 343 с.

8. Данилов С. В., Куклина А. А. Текстура горячекатаной электротехнической анизотропной стали [Электронный ресурс] // XV международная научно-техническая Уральская школа-семинар металловедов-молодых ученых, Екатеринбург, 8-12 декабря 2014 г.: сборник научных трудов. - Екатеринбург : УрФУ, 2014. - С. 293-295. URL: http://hdl.handle.net/10995/29761.

9. Canova G. R., Kockss U. F., Jonas J. J. Theory of torsion texture development // Acta Metallurgica. - 1984. - Vol. 32, iss. 2. - P. 211-226. - DOI: 10.1016/0001-6160(84)90050-6.

10. Технология изготовления бесшовных (цельнотянутых) труб [Электронный ресурс] / Сварка металлов. - URL: http://www.tehnoarticles.ru/svarkametalla/14.html.

11. Преображенский А. А., Бишард Е. Г. Магнитные материалы и элементы. - М. : Высш. шк., 1986. - 352 с.

12. Cayron C. One-step model of the face-centred-cubic to bodycentred-cubic martensitic transformation // Acta Crystallographica Section A: Foundations of Crystallography. - 2013. - Vol. 69, iss. 5. - P. 498-509. - DOI: 10.1016 / 0001-6160 (84) 90050-6. 